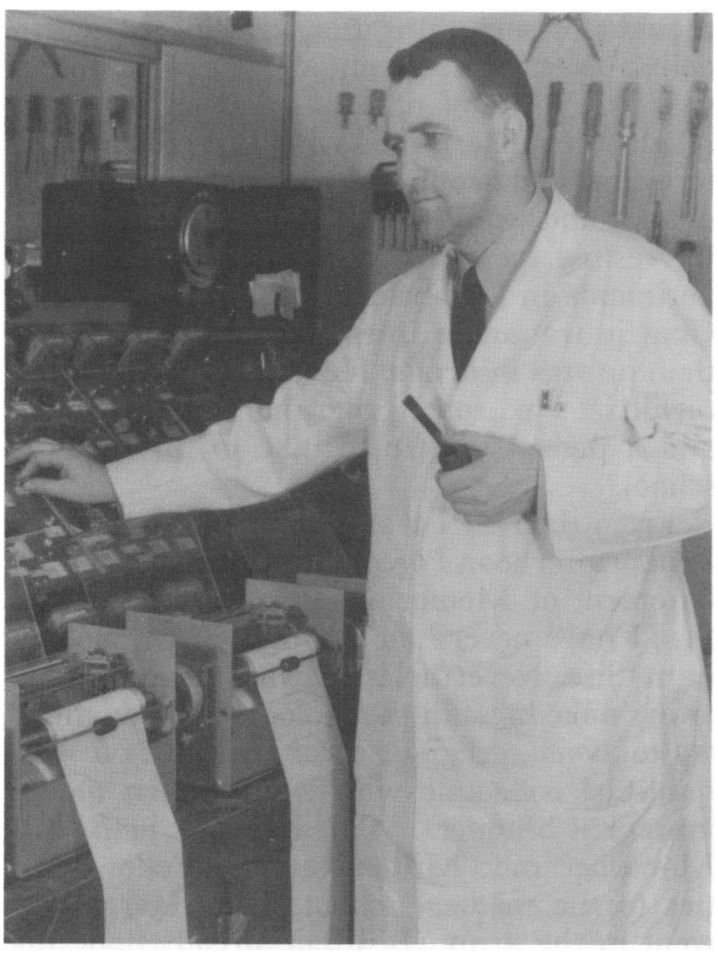

Joseph V. Brady, 1955.

influenced my personal and professional life, as I'm sure many of my colleagues, old and young, will testify. In the early days, I spent a good deal of time in Indianapolis while Charlie Ferster-doing the first editorial job in $1 / 2$ day a week, he claimed-turned the task of making readable English out of our "scientific jargon" over to Marilyn Ferster. He and I would then take off for Alamagordo, New
Mexico, to train chimpanzees for the National Aeronautics and Space Administration's Animal Pretest Flights of Project Mercury. After Charlie turned over his editorial post to John Boren in our laboratories at Walter Reed, it became obvious that this was not a " $1 / 2$ day a week" job and the realities of proprietorship and its burdens became painfully apparent, remaining with us for some years.

One final reminiscence about those early years. Shortly after John Boren took over as Editor of JEAB, Charlie Ferster moved to Maryland and joined us in another ambitious initiative involving the Walter Reed, on the one hand, and the laboratories that Dick Herrnstein, Jack Findley, and I had started at the College Park Campus of the University of Maryland, on the other. Once again, we felt called upon to "open our own store" since neither the University nor the Federal establishment seemed to satisfy our "cutting edge" experimental and applied behavior analysis needs. As a result, the Institute for Behavioral Research was born and shortly thereafter Charlie submitted a paper to JEAB on some of the initial experiments conducted at this independent bastion of scientific freedom. When he received a letter of rejection from John Boren some weeks later, Charlie Ferster confided to me that he thought it might be time for us to start a new journal!

Division of Behavioral Biology Johns Hopkins University School of Medicine

Baltimore, Maryland 21205

\title{
Peter B. Dews
}

\section{AN OUTSIDER ON THE INSIDE}

When I arrived in Boston to join Otto Krayer's Department of Pharmacology at the Harvard Medical School in January 1953, Fred Skinner had already been in contact with Krayer suggesting that he had techniques that might be useful to pharmacologists. (The Harvard Medical School is in Boston separated by a river and about 4 miles from most of the rest of the university, and the Department of Psychology, in Cambridge. Fred had spent time at the medical school when he was a Junior Fellow, in the laboratory of Alex Forbes, and was aware of the potential for good behavioral techniques in medical research. Some years later when he was in Minnesota, he and Heron performed experiments on amphetamine that 
presaged the development of modern behavioral pharmacology.)

At the same time that he was trying to interest pharmacology, Fred was talking to Harry Solomon, a professor of psychiatry and head of the Boston Psychopathic Hospital (now the Massachusetts Mental Health Center) about applying operant techniques to the study of psychotics, suggesting that behavioral deficits were probably more important than the bizarre behavior that mostly occupied people's attention. Out of these latter discussions emerged the project on psychotic subjects at Metropolitan State Hospital conducted by $\mathrm{Og}$ Lindsley with the support of Solomon and his successor, Jack Ewalt.

Within a short time of arriving in Boston I made a visit to Skinner in his laboratories in the basement of Memorial Hall, in the company of Peter Witt, famous for studies on spiders, who was a visiting fellow in pharmacology from Berne, Switzerland. We chatted with Fred for a few minutes and then he said that Charlie Ferster would show us around the laboratory, which he did.

In order to understand why what I saw that morning was immediately fascinating, a little personal history is necessary. The first project I was involved in when I started pharmacology was on the behavioral effects of tetrahydrocannabinols (yes, there was interest in THCs in 1945, and had been for years before that). Studying their behavioral effects in either humans or laboratory animals was frustrating in the extreme. There seemed to be no methods available to study behavioral effects of drugs continuously in real time in the manner we were accustomed to studying the physiological effects. The paper of Skinner and Heron of 1938 was published in a psychological journal and had no effect on pharmacology that I have been able to detect. No progress was made in the studies on THC in 1945 and 1946.

When Charlie showed me the pigeon laboratory in early 1953, it was immediately apparent from the counters and cumulative records that behavioral phenomena were being studied in a way that was well suited for application to pharmacology. In spite of my reservations about pigeons as subjects for drugs, in a short time we had planned a joint project, on effects of pentobarbital on fixed-interval responding, and immediately started experiments. Charlie was like that; if he or Fred thought of something they considered worth doing, they immediately started pilot observations. A sort of natural selection based on results then determined what lines seemed interesting and would be continued and what did not and would not. The drug results were interesting from the start but doing the experiments in Cambridge was not convenient. Charlie was more interested in proselytizing than he was in drugs. He lent me a converted picnic ice box, some programming apparatus, and a pigeon or two to take to the medical school.

From then on I was a constant attender at Friday afternoon Pigeon Staff Meetings in the basement of Memorial Hall despite the fact that I have never had a course in psychology in my life. Nevertheless, I was uncomfortable at my nakedness in psychology, and sought to try to avoid egregious error by having a well qualified colleague who would warn me of imminent blunders. With Krayer's help, Bill Morse became a Milton Research Fellow with ties to the medical school. Dick Herrnstein went in the army (Bill had already done his stint) and so Bill stayed in Cambridge until a year or two later, when Lew Gollub was ready to take over the daily operation of the "Pigeon Laboratory." He then moved over to the medical school full time. It was the best thing that could have happened to the laboratory. We complemented one another and he taught me a great deal of which psychology was a small part.

Meanwhile, Pigeon Staff Meetings were an exciting weekly experience. With unbelievable frequency, important and unexpected findings were presented, informally, as the power of "schedules" was revealed in area after area of psychological interest. The graduate students assumed that this was what life in science was like, but of course it was a golden period. "We are skimming the cream," said Charlie. Regular attendees and visitors to Pigeon Staff Meetings during those halcyon years have been chronicled by more reliable sources. They included essentially all the seminal contributors to the experimental analysis of behavior. I do not remember Fred Keller attending but his influence was ubiquitous through Ferster and his other students. I was proud to be accepted as a member of so productive and exciting a group.

But all was not completely well. The dis- 


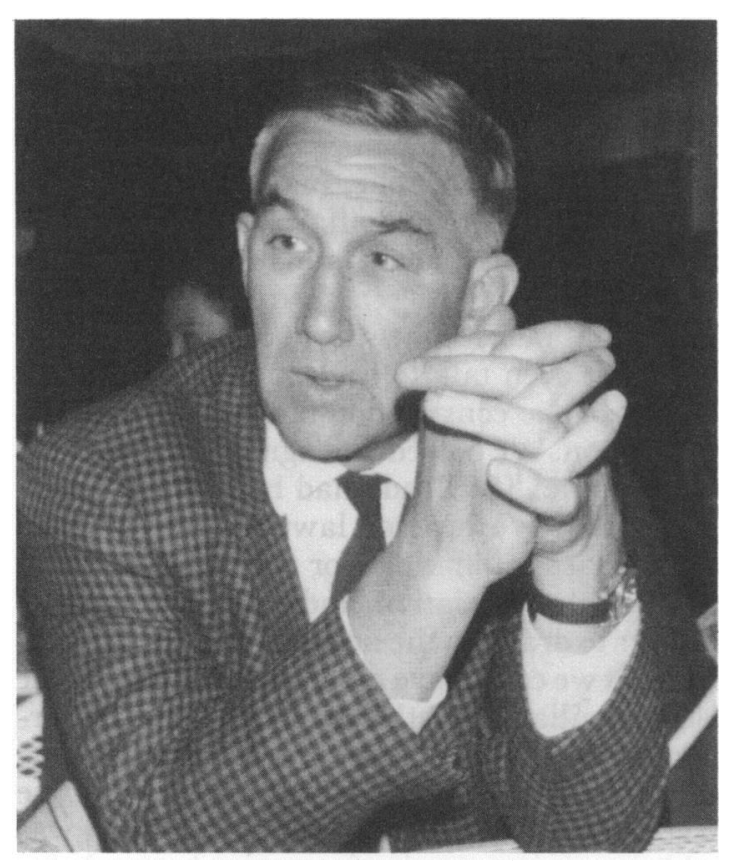

Peter B. Dews, 1968.

coveries that were made were not reaching the outside world as efficiently as they should. Partly, people were too busy making discoveries to be willing to divert long hours to the preparation of proper scientific papers. When they did bring themselves to take the time, manuscripts were received by the leading organs with hostility. The papers paid insufficient tribute to the golden calves of theory, and included insufficient agricultural statistics. And, admittedly, the subject matter was unfamiliar. Who had ever heard of the importance in psychology of the powerful influence of details of programming of events in real time, what was being called schedules? Charlie was astute and worldly enough to know that even the greatest discoveries that are not properly communicated have little impact: vide Mendel. So the notion of starting a journal gradually took shape. It would be a journal that would publish significant findings in the experimental analysis of behavior, even if the results neither illuminated a contrived theory nor presented F-tests. The eclecticism of the founders was reflected in the fact that, despite my lack of psychological credentials save for some technical proficiency and one or two publications in the field, I was accepted without question as an equal in launching the journal.
There was no question that Charlie Ferster was prime mover in founding JEAB. He had had unwarrantedly callous treatment from the Journal of Comparative and Physiological Psychology. I don't think he had had many papers actually rejected, but one paper came back with the remarkably brutal comment by a reviewer, "Small fish, throw it back."

Charlie had put most of his writing effort into Schedules of Reinforcement and was less worried than Murray Sidman that JCPP was stunting his career, a real concern of Murray's. Nevertheless, Charlie was always talking about how fragile writing behavior was, and how easily it could be inhibited by punishment by cruel editors. Hence his evident concern in his initial statement of editorial policy that such behavior of editors would not be permitted in JEAB. He strongly maintained that poor or unreadable papers didn't really hurt a journal, readers simply flipped past the rubbish, only paper was wasted, and "paper is cheap." The good papers would be read and would assure subscriptions. Murray strongly supported him. Both were insistent on single-subject presentations, no averaging across subjects and no statistics.

It is an interesting example of Galtonian regression to see how quickly editorial policy moved towards that of other journals, even while Charlie was still editor. I had had reasonably fair experience with pharmacology journals and was much less paranoid (as I thought then) about journal policies. But, in retrospect, I think JCPP probably treated Charlie and Murray as unfairly as they thought. The first research grant application I submitted, probably in 1953 or 1954, was not funded (I can't remember whether it was disapproved or just not funded) and Harry Harlow, the Editor of JCPP, who chaired the Study Section, wrote me a letter in which he said, in effect, that their group was not competent to judge pharmacology, but as for the operant conditioning part, they were not going to approve that because the operant conditioning experiment had already been done. With that attitude, how would he ever publish any papers in the field in his journal?

We were anxious to keep the cost of publishing JEAB to a minimum, most of us because we were a bit in awe of the undertaking and were unsure we could obtain enough subscribers to make it self-sustaining. Charlie 
wanted to keep costs down so that the subscription price could be kept low enough to be affordable to everybody, thereby spreading the word as widely as possible. We were thus interested in applying to the post office for second-class mailing privileges. Somebody quickly found out that the application had to be made by an organization. Charlie did not care much for organizations, regarding them as mechanisms for keeping people out, but was sufficiently interested in keeping costs down to overcome his distaste. And so we formed the Society for the Experimental Analysis of Behavior (SEAB) at a meeting during the summer of 1957, agreeing that its sole purpose would be to publish JEAB and that membership would be limited to those involved in editing the journal. Thus membership would be temporary and there was no way anybody but the editor could develop any "power" through membership.

After the vote, we turned to $\mathrm{Og}$ Lindsley, the Business Manager, and suggested that he could now apply for the valuable permit. He objected, saying that the creature we had just devised was not a real organization, that it still was just a bunch of guys editing a journal; that we needed to be incorporated and have statutes and by-laws and officers and an annual meeting announced in advance. Otherwise we would all be personally liable for everything from libel to a damage suit lodged by a mailman who had hurt his back while carrying a load of JEABs. No one paid attention to him and we went back to the important business of solving the many logistical problems involved in getting the journal published. As I recall,
Og sat through the rest of the long meeting under protest, maintaining a steady background commentary on the irresponsibility of the rest of us. I remember thinking it strange because Og was sort of casual about important aspects of his personal affairs, such as passing the required German examination for the $\mathrm{PhD}$.

Needless to say, Og came to the next meeting with the news that the postal authorities wouldn't even talk to him until he gave them a copy of the constitution of the applicant organization. We bowed and agreed that we must incorporate. Joe Brady had had a recent contact with a Washington lawyer who had done somewhat similar work for the American Psychological Association and we engaged that lawyer to draw up the necessary papers, thinking that we could save money by using someone very familiar with the needs of scientific organizations. But the business of incorporating dragged on for months and at the end of it we were sick of the whole process. And insult was added to injury in the form of a lawyer's fee that we considered excessive for what to us seemed a trivial amount of work.

Incidentally, I was probably the first to have a paper recommended for rejection by JEAB, the grounds being that the experimental design was unbalanced; there were empty cells. Though the reviewer was a friend of his, Charlie was outraged and promptly published the paper.

Laboratory of Psychobiology
Department of Psychiatry
Harvard Medical School
Boston, Massachusetts 02115

Laboratory of Psychobiology Department of Psychiatry Boston, Massachusetts 02115

\section{Thom Verhave}

\section{FADED IMAGES}

When asked to joggle my memory about the early days of JEAB, it struck me how little I did remember. All I could come up with were two anecdotes relevant to the editorial policy of the first few years. Conversations with my wife, Anneke, triggered a number of other rec- ollections. However, I was astonished to be told that I had been Secretary-Treasurer of the Journal for several years. I must have and a look at the early issues of JEAB confirms it, but I do not remember a thing about that. I may well have contributed $\$ 50$ or whatever, 